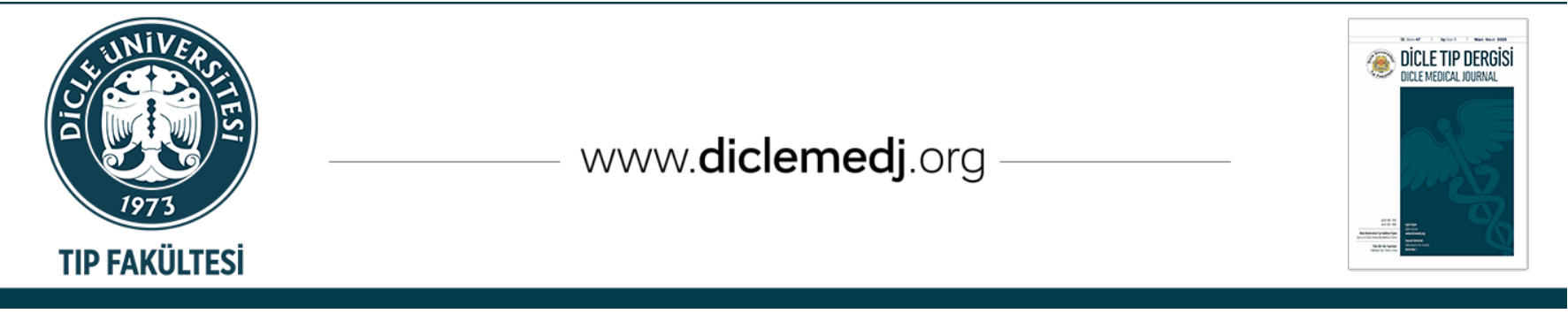

Original Article / Özgün Araştırma

\title{
Cerebral Hemodynamic Response To Menstrual Cycle In Migraine
}

\author{
Ayca Ozkul ${ }^{1}$ 1, Hasibe Ozgecen Dincel ${ }^{D}{ }_{1}$, Ali Akyol ${ }^{(D)} 1$ \\ 1 Adnan Menderes University, Faculty of Medicine, Department of Neurology, Aydin, Turkey \\ Received: 11.07.2020; Revised: 07.09.2020; Accepted: 16.09.2020
}

\begin{abstract}
Objective: Menstrually related migraine (MRM) occurs in relation to menstrual cycles. We investigated the cerebral hemodynamic response to the menstrual cycle in nonmenstrually related migraines (nMRM), MRM and healthy controls.

Methods: 22 nMRM, 20 MRM patients in an attack-free interval and 20 healthy volunteers were included in our study. TCD recordings were made during the follicular and luteal phases of the hormonal cycle and mean flow velocity values of middle and posterior cerebral arteries were studied. Cerebral vasomotor reactivity (CVR) was evaluated by breath holding index (BHI) and visually evoked blood flow (VEBF) changes in both phases of the same menstrual cycle.
\end{abstract}

Results: Mean flow veloticities and hormone levels were not different between groups. Right BHI and bilateral VEBF values were significantly lower in both of the migraine groups. The physiological elevation of CVR in the luteal phase was detected in the control and nMRM groups, but not in the MRM group.

Conclusion: The cerebral hemaodynamics were affected in both MRM and nMRM. Additionally the physiological CVR to menstrual cycle was impaired in MRM. The impairment in cerebral hemodynamic response to the menstrual cycle in MRM needs further research to discover the underlying pathophysiology.

Keywords: migraine, headache, transcranial doppler, cerebral hemodynamics, menstruation

DOI: $10.5798 /$ dicletip.799867

Correspondence / Yazıșma Adresi: Ayca Ozkul, Adnan Menderes University Medicine Faculty, Neurology Department 09100 Aydin, Turkey e-mail: ozkulayca@hotmail.com 


\section{Migrende Menstruel Siklusa Serebral Hemodinamik Yanıt}

Öz

Giriş: Menstruasyon ilişkili migren (MIM) doğurganlık çağındaki kadınlarda menstruel siklus ile ilişkili belirir. Biz menstruel siklustaki serebral hemodinamik yanıtı menstruasyon ilişkli olmayan (nMIM), ve olan (MIM) migrenliler ve sağlıklı kontrollerde inceledik.

Yöntemler: 22 nMIM, 20 MIM ataksız dönemdeki hasta ve 20 sağlıklı gönüllü çalışmamıza dahil edildi. Transkranial Doppler (TKD) kayıtları hormonal siklusun folikuler ve luteal fazlarında yapıldı ve orta ve posterior serebral arterlerin ortalama akım velositeleri çalışıldı. Serebral vazomotor reaktivite, breath holding index (BHI) ve visual evoked kan akımı (VEKA) değişiklikleri ile aynı menstruel siklus her iki fazında değerlendirildi.

Bulgular: Ortalama akım velositeleri ve hormon seviyeleri gruplar arasında farklı değildi. Sağ BHI ve bilateral VEKA değerleri her iki migren grubunda belirgin düşüktü. Luteal fazdaki serebral vazomotoro reaktivite fizyolojik artışı kontrol ve nMIM gruplarda izlenirken MIM grubunda görülmedi.

Sonuç: Serebral hemodinamikler hem MIM hem nMIM'de etkilenir. Ilaveten menstruel siklusta fizyolojik serebral vazomotor yanıt MIM'de bozulmuştur. MIM'de serebral hemodinamik yanıtın bozulması üzerine ileri çalışmalara alta yatan patofizyolojiyi keşfetmek için ihtiyaç vardır.

Anahtar kelimeler: migren, başağrısı, transkranial doppler, serebral hemodinamik, menstruasyon.

\section{INTRODUCTION}

In over half of women migraineurs, the headaches are strictly related to their menstrual cycle ${ }^{1,2}$. Menstrually related migraine (MRM) is defined as attacks which are most likely to occur in the period between 2 days before the onset of menstruation and the first 3 days of the bleeding cycle in at least two of three consecutive menstrual cycles. Migraine attacks with or without aura can occur at other times of the cycle $^{2,3}$. MRM also differs from non-menstrually related migraine (nMRM) by having attacks with severity, long duration, unresponsiveness to medical treatments, and a higher rate of recurrence and work related disability ${ }^{4}$.

The other aspects to be investigated are cerebral vasomotor reactivity (CVR) changes and the role of vascular abnormalities in nMRM and MRM. In spite of the fact that migraine in young women represents a risk factor for ischemic stroke ${ }^{5}$, which is elevated by administration of combined oral contraceptives, there is no data about cerebral hemodynamic changes in MRM. Although there are numerous studies of vasomotor reactivity in migraine patients, this has not previously been studied in MRM patients. It has been reported that endogenous estrogen affects cerebral blood flow velocity under normal physiological conditions in premenopausal women ${ }^{6}$. Therefore, evaluation of CVR may be changed during different phases of the menstrual cycle, especially in MRM. Estrogen-induced changes in cerebral hemodynamics have to be considered in such patients. We investigated CVR changes in anterior and posterior circulation during the menstrual cycle in patients with nMRM and MRM and in healthy controls in this study.

\section{METHODS}

22 patients with nMRM (age $30.25 \pm 8.6$ years), 20 MRM cases (age $32.65 \pm 8.75$ years) and 20 healthy volunteers (age $30.25 \pm 8.6$ years) were included. IHS- 2004 diagnosis criteria was used fort he diagnosisi of migraine (2) and a questionnaire was prepared to assess aura, side of headache, hand dominancy, migraine attack frequency and severity using a visual analog scale (VAS). In order to compare MRM with and without aura patients were selected based on their aura in the MRM group. MRM patients having migraine attacks with aura at any time during the menstrual cycle were defined as MRM with aura. Patients with hematological or endocrinological disorders, psychiatric illness, hypertension, 
dyslipidemia, infection, epilepsy, cardiac and cerebrovascular disease, or irregularities in menstrual cycle were all excluded (Table 1). None of the participants had used oral contraceptives, smoked, had migraine prophylaxis therapy, or taken analgesics, alcohol or caffeine in the previous 48 hours. All patients were examined during an attack free interval. Transcranial Doppler (TCD) recordings were made during the follicular (3-8 days of the menstrual cycle) and luteal (18-23 days of the menstrual cycle) phases of the same hormonal cycle by the same physician. Follicular and luteal estrogen, progesteron, LH and FSH blood levels were also examined in all participants in order to evaluate their hormone profile.

Table I: Demographic and clinical characteristics of the groups studied

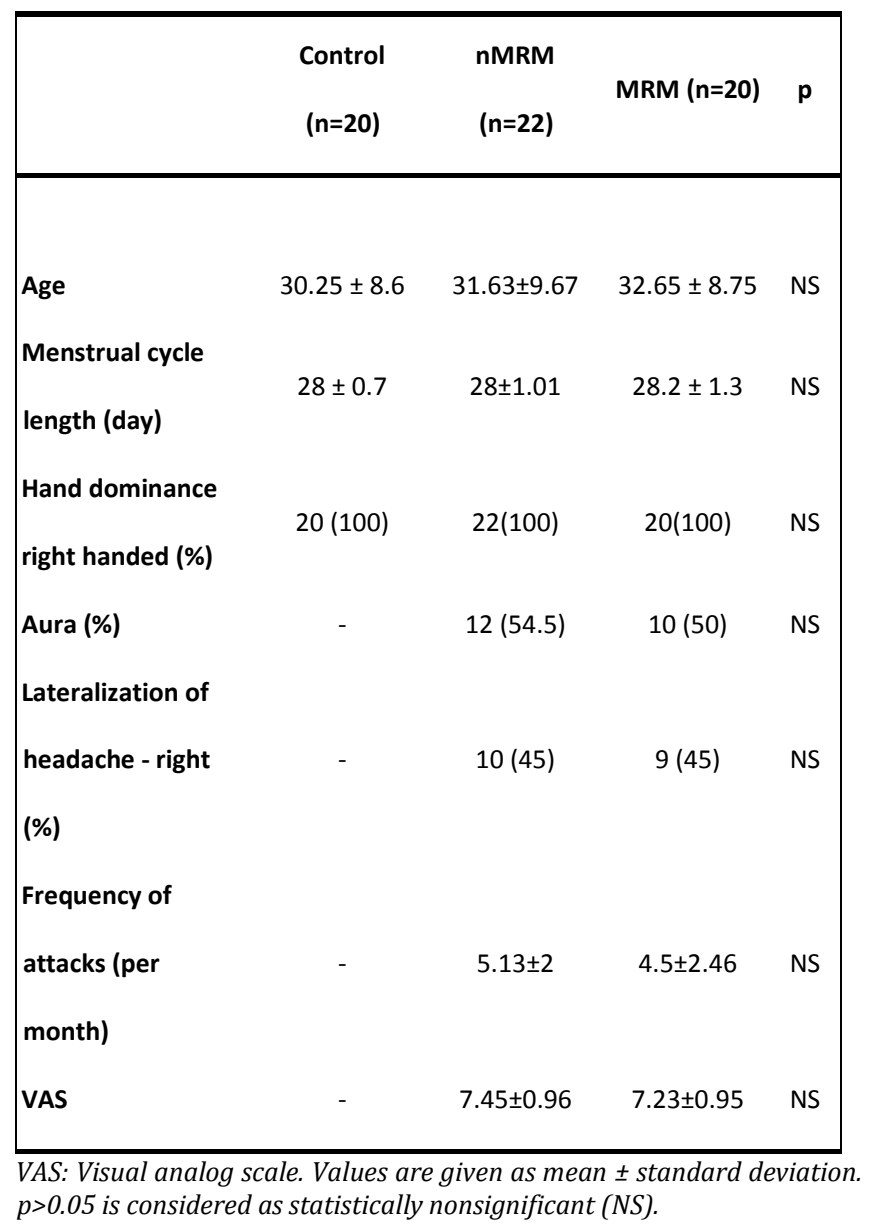

All examinations were performed by the same TCD ultrasonographer, who was blinded to the clinical status of the subjects. The mean flow velocity at rest was obtained by the continuous recording of a 1-minute period of normal room air breathing. The reactivity of each pair of homologous vessels was examined by calculating the breath-holding index (BHI), which was repeated three times with intervals of 120 seconds of normal breathing and then averaged. The BHI was calculated as the percentage increase in MCA mean flow velocity occurring during breath-holding divided by the length of time (20 seconds) the subjects held their breath after a normal inspiration. ([Vbh $\mathrm{Vr} / \mathrm{Vr}] \times 100 \times \mathrm{s}-1$, where $\mathrm{Vbh}$ is MCA mean blood velocity at the end of breath-holding, $\mathrm{Vr}$ is the MCA mean blood velocity at rest, and s-1 per second of breath-holding.

Both P2 segments of PCAs were insonated through the temporal bone window for measuring visual evoked blood flow (VEBF). All subjects were monitored during 10 cycles of 20 seconds with eyes open and looking around followed by 20 seconds with eyes closed to assess mean flow velocity changes of PCA. VEBF was defined as a relative increase of $\mathrm{BFv}$, which was calculated as the percentage change in the baseline value. (VEBF $=100 x(v s-v r) / v r$, where vs is the maximal PCA mean velocity when the stimulus was on, and vr is the PCA minimal mean velocity with the stimulus off.) The study was approved by the local ethics committee of our university (2009/00346).

\section{Statistical Analyses}

We used Statistical Package for the Social Sciences (SPSS) 18.0 (SPSS Inc., Chicago, IL, USA) for statistical analysis. Results were given as mean \pm standard deviation. Mann-Whitney U-test and Chi square tests were used to analyze variables. $\mathrm{p}<0.05$ was considered statistically significant for all comparisons.

\section{RESULTS}

We found no statistically significant difference between groups in terms of age or duration of menstrual cycle. All of the participants were 
right handed. nMRM and MRM patients were also compared for the presence of aura, the side and severity of headache and the attack frequency, but no difference was found (Table 1). In the TCD evaluation, baseline MCA and PCA mean flow velocity values detected in the follicular and luteal phases were not significantly different between groups (Table 2). Follicular and luteal right BHI and bilateral VEBF values were found to be lower in the nMRM and MRM groups than in the controls. Left BHI values of the follicular and luteal phases were seen to be lower in the MRM and nMRM groups, but this was not statistically significant (Table2).
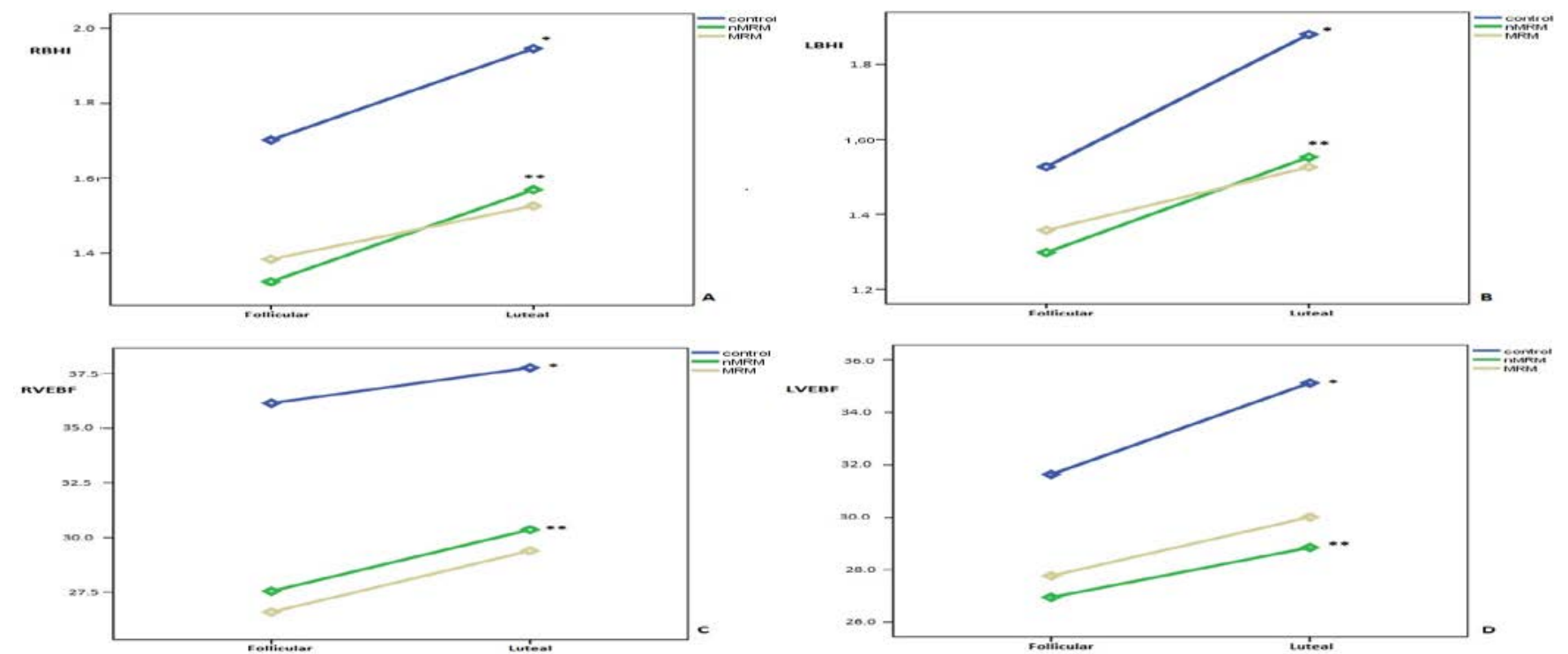

Figure 1: Figure showing the elevation of cerebral vasomotor reactivity in the luteal phase in both control and nMRM groups but not in MRM patients. In comparison of right BHI ${ }^{*} \mathrm{p}=0.04,{ }^{* *} \mathrm{p}=0.003(\mathrm{~A})$, in left BHI ${ }^{*} \mathrm{p}=0.01,{ }^{* *} \mathrm{p}=0.001(\mathrm{~B})$, in right VEBF ${ }^{*} \mathrm{p}=0.04$, ${ }^{* *} \mathrm{p}=0.00(\mathrm{C})$ and in left VEBF ${ }^{*} \mathrm{p}=0.003,{ }^{* *} \mathrm{p}=0.00(\mathrm{D})$.

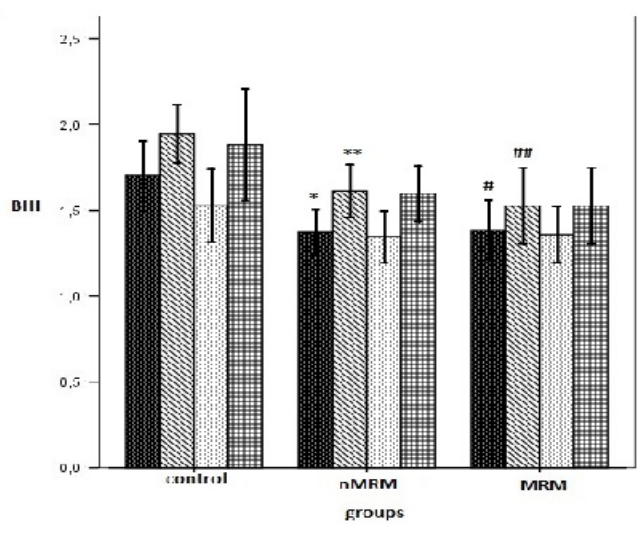

Figure 2: Figure showing the differences of BHI values betwen groups ( ${ }^{*} \mathrm{p}=0.01$, ${ }^{* *} \mathrm{p}=0.008 \mathrm{nMRM}$ vs control, $\# p=0.02$,\#\#p=0.001 MRM vs control).
When we compared the blood flow velocities of the nMRM and MRM groups, we found no statistical significance (Table 2). Additionally, there was an elevation of BHI and VEBF values in the luteal phase compared to the follicular phase of the menstrual cycle in the control and nMRM groups. Although the cerebral vasomotor reactivity values were closer in both migraine groups, the same elevation was not detected in MRM patients (Table 2, Figure 1,2,3). Nor did we detect any significant difference in estrogen, progesterone, LH or FSH levels (Table 2). 
Table II: Comparison of TCD parameters studied including mean flow velocity (cm/s), BHI and VEBF responses and also hormone levels during follicular and luteal phases between groups

\begin{tabular}{|c|c|c|c|c|}
\hline & $\begin{array}{l}\text { Control } \\
(n=20)\end{array}$ & $\begin{array}{l}\text { nMRM } \\
(n=22)\end{array}$ & $\begin{array}{c}\text { MRM } \\
(n=20)\end{array}$ & $\mathbf{p}$ \\
\hline \multicolumn{5}{|l|}{ Follicular phase } \\
\hline RBHI-f & $1.70 \pm 0.43$ & $1.37 \pm 0.30$ & $1.4 \pm 0.36$ & 0.02 \\
\hline RMCA Vmean-f & $57.55 \pm 8.91$ & $61.04 \pm 11.83$ & $63.25 \pm 9.74$ & NS \\
\hline LBHI-f & $1.53 \pm 0.45$ & $1.34 \pm 0.33$ & $1.35 \pm 0.34$ & NS \\
\hline LMCA Vmean-f & $54.15 \pm 11.13$ & $57.63 \pm 10.30$ & $60.7 \pm 10.74$ & NS \\
\hline RVEBF-f & $36.1 \pm 13.14$ & $27.0 \pm 4.18$ & $26.6 \pm 6.17$ & 0.00 \\
\hline RPCA Vmean-f & $40.45 \pm 9.80$ & $41.18 \pm 5.54$ & $39.9 \pm 7.45$ & NS \\
\hline LVEBF-f & $31.63 \pm 3.35$ & $26.4 \pm 4.16$ & $27.7 \pm 6.9$ & 0.002 \\
\hline LPCA Vmean-f & $41.10 \pm 5.59$ & $39.86 \pm 4.85$ & $39.6 \pm 6.55$ & NS \\
\hline Estrodiol-f & $52.66 \pm 22.46$ & $66.54 \pm 38.59$ & $57.23 \pm 24.82$ & NS \\
\hline Progesteron-f & $0.49 \pm 0.25$ & $0.7 \pm 0.41$ & $0.53 \pm 0.19$ & NS \\
\hline LH-f & $4.8 \pm 1.77$ & $5.26 \pm 2.11$ & $5.65 \pm 4.27$ & NS \\
\hline FSH-f & $7.66 \pm 4.43$ & $7.61 \pm 3.23$ & $9.2 \pm 7.62$ & NS \\
\hline \multicolumn{5}{|l|}{ Luteal phase } \\
\hline RBHI-I & $1.94 \pm 0.36$ & $1.67 \pm 0.34$ & $1.53 \pm 0.47$ & 0.003 \\
\hline RMCA Vmean-l & $57.6 \pm 5.1$ & $60.36 \pm 0.48$ & $62.45 \pm 10.3$ & NS \\
\hline LBHI-I & $1.88 \pm 0.69$ & $1.6 \pm 0.36$ & $1.52 \pm 0.47$ & NS \\
\hline LMCA Vmean-l & $55.2 \pm 9.88$ & $62.54 \pm 12.09$ & $60.35 \pm 10.0$ & NS \\
\hline RVEBF-l & $37.8 \pm 9.1$ & $29.91 \pm 4.0$ & $29.3 \pm 5.56$ & 0.00 \\
\hline RPCA Vmean-l & $40.15 \pm 3.11$ & $42.40 \pm 6.18$ & $41.35 \pm 6.68$ & NS \\
\hline LVEBF-I & $35.12 \pm 4.32$ & $28.4 \pm 3.31$ & $30.0 \pm 5.10$ & 0.00 \\
\hline LPCA Vmean-l & $39.75 \pm 5.78$ & $40.95 \pm 6.16$ & $44.45 \pm 6.9$ & NS \\
\hline Estrogen-l & $127.46 \pm 45.97$ & $142.7 \pm 64.04$ & $132.99 \pm 52.89$ & NS \\
\hline Progesteron-I & $6.46 \pm 3.9$ & $7.06 \pm 3.95$ & $6.99 \pm 4.19$ & NS \\
\hline LH-l & $6.07 \pm 4.7$ & $6.30 \pm 4.23$ & $7.3 \pm 6.0$ & NS \\
\hline FSH-l & $4.46 \pm 3.6$ & $3.89 \pm 2.31$ & $4.08 \pm 2.68$ & NS \\
\hline
\end{tabular}

RBHI: right BHI, LBHI: left BHI, RVEBF: right VEBF, LVEBF: left VEBF, Vmean: mean velocity. Values are given as mean \pm standard deviation. $p>0.05$ is considered as statistically nonsignificant (NS).

Table III: Changes of cerebrovasomotor reactivity in follicular(f) and luteal (l) phases between migraine groups with and without aura

\begin{tabular}{|c|c|c|c|c|c|c|c|c|c|c|c|c|c|}
\hline & & RBHI-f & RBHI-I & $\mathrm{p}$ & LBHI-f & LBHI-I & $\mathrm{p}$ & RVEBF-f & RVEBF-I & $\mathrm{p}$ & LVEBF-f & LVEBF-I & $\mathrm{p}$ \\
\hline \multirow[t]{2}{*}{ nMRM } & $\begin{array}{l}\text { Aura(+) } \\
(n: 12)\end{array}$ & $141022 \pm 0.22$ & $1.66 \pm 0.26$ & 0.03 & $1.31 \pm 0.3$ & $1.55 \pm 0.28$ & 0,008 & $27.99 \pm 4.44$ & $30.47 \pm 4.36$ & 0,004 & $27.32 \pm 4.14$ & $29.2 \pm 2.9$ & 0,002 \\
\hline & $\begin{array}{l}\text { Aura(-) } \\
(\mathrm{n}: 10)\end{array}$ & $1.32 \pm 0.38$ & $1.68 \pm 0.43$ & 0.0047 & $1.38 \pm 0.38$ & $1.65 \pm 0.45$ & 0.04 & $25.91 \pm 3.76$ & $29.25 \pm 3.64$ & 0.013 & $25.25 \pm 4.10$ & $27.46 \pm 3.71$ & 0.008 \\
\hline \multirow[t]{2}{*}{ MRM } & $\begin{array}{l}\text { Aura(+) } \\
(\mathrm{n}: 10)\end{array}$ & $1.42 \pm 0.42$ & $1.61 \pm 0.38$ & NS & $1.45 \pm 0.39$ & $1,62 \pm 0.38$ & NS & $27.52 \pm 7,08$ & $30.1 \pm 4.75$ & NS & $28.3 \pm 6.7$ & $30.2 \pm 4.78$ & NS \\
\hline & $\begin{array}{l}\text { Aura(-) } \\
(\mathrm{n}: 10)\end{array}$ & $1.34 \pm 0.32$ & $1.44 \pm 0.56$ & NS & $1.27 \pm 0.28$ & $1.43 \pm 0.6$ & NS & $25.6 \pm 5.32$ & $28.6 \pm 6.42$ & NS & $27.3 \pm 7.42$ & $29.7 \pm 5.65$ & NS \\
\hline
\end{tabular}

Values are given as median \pm standart deviation. $p>0.05$ means statistcally nonsignificant (NS) 
In addition to these results we compared the cerebral vasomotor reactivity data of migraine patients (MRM and nMRM) with and without aura (Table 3). Although the elevation of BHI and VEBF values in luteal phase was both detected in nMRM with and without aura, the same luteal phase elevation of cerebral vasomotor reactivity response couldn't be found statistically in the MRM subgroups (with and without aura). Aura had no effect on this physiological cerebral vasomotor reactivity changes.

\section{DISCUSSION}

Migraine is regarded as a vasomotor disorder with a complex pathogenesis. TCD may help to understand its pathophysiology since it enables assessment of cerebral hemodynamic changes not only during migraine attacks but also interictally. However, there are conflicting data on blood flow changes in the headache-free period of migraineurs ${ }^{7-10}$. In our study we studied bilateral MCA and PCA mean flow velocities but found no significant difference between healthy subjects and migraineurs.

Haring et al. also worked on cerebral blood flow and showed no changes in migraine with and without aura, or in controls during attacks as well as in the interictal period 7 . Similar results were also found by Zwetsloot et al. ${ }^{8}$. In contrast to these data, higher values of cerebral blood flow velocity were recorded in both anterior and posterior circulation in migraine with and without aura in comparison to healthy controls, suggesting increased vascular tone during a headache-free interval in migraineurs ${ }^{9,10}$. All these conflicting results probably arise from differences in methodologies of the studies.

Regulation of blood flow in the human brain is complex and basal cerebral blood flow value is inadequate to define the cerebral hemodynamic status. Therefore the similiar mean flow velocities between the studied groups are less valued. In order to evaluate cerebral hemodynamia there is a need for investigating CVR.

Although in our study MCA and PCA mean flow velocities didn't differ between groups, cerebral vasomotor reactivity results were statistically different. In the MRM and nMRM groups, right BHI and bilateral VEBF values detected in the follicular and luteal phases were found to be lower than in control group. Left BHI was also lower in two migraine groups but this was not statistically significant. Our data suggest that there is an impaired cerebral hemodynamic response in both anterior (mainly right side) and bilateral posterior circulations in nMRM and MRM patients. BHI and VEBF are commonly used parameters derived from cerebral blood flow to study vasomotor response. Unfortunately, the findings in the literature are quite varied for migraine patients. Increased ${ }^{11}$, decreased or similar ${ }^{12}$ vasomotor response between controls and migraineurs have all been reported in previous TCD studies measuring BHI. In another study data suggested impaired adaptive cerebral hemodynamic response in the posterior circulation in migraine with aura but not in migraine without aura ${ }^{13}$. In another study, an impairment of cerebral hemodynamics in posterior but not in anterior circulation in migraine patients was found 14 . Additionally, VEBF was used for posterior circulation assessment but no statistical difference was found between the migraine and control groups ${ }^{15}$.

Variability in the methodology of these studies makes it difficult to reach definite conclusions. The different methodology of studies, small study groups, patient clinical characteristics and time of investigation may cause these conflicting results. Despite all discrepancies, cerebral vasoreactivity is affected in migraineurs.

Decreased estrogen occurring in the late luteal phase prostaglandin release, changes in opioid tonus, increased sensitivity of dopamine 
receptors and serotonergic transmission, altered CVR to serotonin, and changes in nocturnal melatonin increase may be involved in pathogenesis ${ }^{16,17}$.

In literature nMRM and MRM patients exhibited marked clinical differences. Although MRM attacks were longer in duration than nMRM attacks, they rated slightly more severe and frequently accompanied by disability of longer duration and there was no difference in the occurrence of any of the migraine-associated symptoms in both migraineur groups ${ }^{18}$. Thus MRM is qualitatively similar to nMRM but more severe and disabling. However, there is as yet no data on the cerebral hemodynamic differences in either type of migraine.

It is also well-known that migraine, in particular with aura, is a risk factor for cerebrovascular diseases, especially in young women ${ }^{19}$. The relative risk of stroke in migraineurs is about two-fold, and increases with the coexistence of female gender, cigarette smoking and combined oral contraceptive use ${ }^{19,20}$.

It has been also documented that there is a cyclic variation in endothelial function ${ }^{21,22}$, and the frequency of myocardial ischemia in premenopausal women with variant angina. The researchers demonstrated a menstrual cyclic variation of myocardial ischemia in premenopausal women which was associated with the variation in estrogen levels ${ }^{23}$. Therefore, it is of interest to find out whether menstrual cycle might be associated with cerebral hemodynamics in premenopausal nMRM patients as well as in MRM patients.

In spite of the fact that there was no significant difference between the groups studied in terms of hormonal status including estrogen, progesteron, LH and FSH, lower BHI and VEBF values in both follicular and luteal phases were detected in the migraine groups. Cerebral vasomotor reactivity values of nMRM and MRM patients were significantly lower. Although BHI and VEBF of both folicular and luteal phases in the nMRM group seemed to be higher than in the MRM group, this did not show any statistical significance in our study.

In previous studies it has been also shown that there is a physiological response of cerebral hemodynamics to the menstrual cycle. Diomedi found higher BHI in females during the ovulatory phase than in the menstrual phase ${ }^{24}$. Similiar results have been also reported as a physiological decrease in the pulsatility index (PI) of the internal carotid artery (ICA) during the late follicular phase, which may be attributed to a decrease in cerebrovascular resistance. Their data suggested that cerebral vascular response in young healthy women is modulated by estrogen. There are also many studies suggesting vasodilator effects of estrogen and its relationship with nitric oxide, endothelial function and membrane fluidity of erythrocytes in literature ${ }^{25}$.

Therefore, evaluation of CVR in MRM patients during different phases of the menstrual cycle is important in order to find a possible mechanism of this type of headache. There is no data in the literature about MRM and its relation with estrogen-associated changes in cerebral hemodynamics which might have important pathological or therapeutic clinical effects.

Our data demonstrated the impairment of physiological elevation of CVR due to the luteal phase of the menstrual cycle in MRM patients. Although there was an elevation of BHI and VEBF values in the luteal phase when compared with the follicular phase in the control and nMRM groups, the same elevation could not be detected in MRM patients. In spite of the similiar vasomotor reactivity values of both migraine groups, the difference between follicular and luteal phases could be detected only in nMRM group. This physiological cerebral vasomotor response due to menstrual cycle was impaired in MRM patients, and it influenced not only posterior circulation but also anterior 
circulation. The presence of aura had no effect on this physiological change in luteal phase. Cerebral vasomotor reactivity response of migraine patients (with or without menstrual relation and aura) in two different phases of menstrual cycle has never been studied in literature before. The menstrual cyclicity of trigeminovascular vasodilator system is affected in MRM 26,27 . Our data also showed impaired cerebrovasomotor reactivity in menstrual cycle in MRM which is similiar with this study.

There are also limitations of our study. Despite the fact that MRM patients without migraine attacks at folicular phase were not so common to be found, our study group wasn't so big. There can be found more significant results in larger groups. It is obvious that cerebral vasomotor reactivity changes due to menstrual cycle not only in MRM but also in pure menstrually related migraine patients are study of interest. This can be also investigated in further studies with more detailed larger study groups.

\section{CONCLUSION}

In conclusion, the findings of this study showed that there was no difference between the cerebral blood flow values of healthy controls and nMRM and MRM patients. However, in nMRM and MRM patients the cerebral vasomotor reactivity values (right $\mathrm{BHI}$ and bilateral VEBF) were significantly lower than in the controls. There was also an elevation of vasomotor reaction in the luteal phase when compared with the follicular phase in the control and nMRM groups. Although this was a result of a physiological response to the menstrual cycle, it was not detected in MRM patients. This physiological cerebral vasomotor response was impaired in MRM. This impairment influenced not only posterior circulation but also right anterior circulation. MRM may differ from migraine by impaired cerebral hemodynamic response to the menstrual cycle and needs further research.

Ethics Committee Approval: The study was approved by the local ethics committee of our university (2009/00346).

Declaration of Conflicting Interests: The authors declare that they have no conflict of interest.

Financial Disclosure: No financial support was received.

\section{REFERENCES}

1. Klein E., Spencer D. Migraine frequency and risk of cardiovascular disease in women. Neurology. 2009; 73: 42-3.

2. Headache Classification Committee of the International Headache Society (IHS). The International Classification of Headache Disorders, 3rd edition (beta version). Cephalalgia. 2013; 33: 629-808.

3. Brandes JL. Migraine in women. Continuum (Minneap Minn) 2012 Aug; 18: 835-52.

4. Allais G, Benedetto C. Update on menstrual migraine: from clinical aspects to therapeutical strategies Neurol Sci. 2004; 25: 229-31

5. Kurth T, Schürks M, Logroscino G, et al. Migraine frequency and risk of cardiovascular disease in women. Neurology. 2009 Aug 25; 73: 581-8.

6. Krejza J, Mariak Z, Huba M, et al. Effect of endogenous estrogen on blood flow through carotid arteries. Stroke. 2001; 32: 30-6.

7. Haring HP, Aichner F. Hemodynamic findings in migraine patients on transcranial Doppler sonography. Wien KlinWochenschr 1992; 104: 6205.

8. Zwetsloot CP, Caekebeke JF, Ferrari MD. Lack of asymmetry of middle cerebral artery blood velocity in unilateral migraine. Stroke. 1993; 24: 1335-8.

9. Nowak A, Kaciński M. Transcranial Doppler evaluation in migraineurs. Neurol Neurochir Pol. 2009 Mar-Apr; 43: 162-72.

10. Dora B, Balkan S. Exaggerated interictal cerebrovascular reactivity but normal blood flow 
velocities in migraine without aura. Cephalalgia. 2002May; 22: 288-90.

11. Totaro R, Marini C, De Matteis G, et al. Cerebrovascular reactivity in migraine during headache-free intervals. Cephalalgia 1997; 17: 1914.

12. Silvestrini M, Cupini LM, Troisi E, et al. Estimation of cerebrovascular reactivity in migraine without aura. Stroke. 1995; 26: 81-3.

13. Perko D, Pretnar-Oblak J, Sabovic M, et al. Cerebrovascular reactivity to L-arginine in the anterior and posterior cerebral circulation in migraine patients. Acta Neurol Scand. 2011 Oct; 124: 269-74.

14. Min JH, Kwon HM, Nam H. The effect of propranolol on cerebrovascularreactivity to visual stimulation in migraine. J Neurol Sci. 2011 Jun 15; 305: 136-8.

15. Granella F, Sances G, Allais G, et al.Characteristics of menstrual and nonmenstrual attacks in women with menstrually related migraine referred to headache centers. Cephalalgia. 2004; 24: 707Y716.

16. Welch KMA, Brandes JL, Berman N. Mismatch in how estrogen modulates molecular and neuronal function may explain menstrual migraine. Neurol Sci. 2006; 27: 190-2.

17. Pinkerman B, Holroyd K. Menstrual and nonmenstrual migraines differ in womenwith menstrually-related migraine. Cephalalgia. 2010 Oct; 30: 1187-94.

18. MacGregor EA, Victor TW, $\mathrm{Hu} \mathrm{X}$, et al. Characteristics of menstrual vs nonmenstrual migraine: A post hoc, within-women analysis of the usual-care phase of a nonrandomized menstrual migraine clinical trial. Headache. 2010; 50: 528-38.
19. Sacco S, Ricci S, Degan D, et al. Migraine in women: the role of hormones and their impact on vascular diseases. J Headache Pain. 2012 Apr; 13: 177-89.

20. Chrissobolis S, Budzyn K, Marley PD, et al. Evidence that estrogen suppresses rho-kinase function in the cerebral circulation in vivo. Stroke 2004; 35: 2200-05.

21. Hiroki J, Shimokawa H, Mukai Y, et al. Divergent effects of estrogen and nicotine on Rho-kinase expression in human coronary vascular smooth muscle cells. Biochem Biophys Res Commun. 2005; 326: 154-9.

22. Williams MR, Westerman RA, Kingwell BA, et al. Variations in endothelial function and arterial compliance during the menstrual cycle. J Clin Endocrinol Metab. 2001; 86: 5389 -95.

23. Kawano H, Motoyama T, Ohgushi M, etal. Menstrualcyclic variation of myocardial ischemia in premenopausal women with variant angina. Ann Intern Med. 2001 Dec 4; 135: 977-81.

24. Diomedi M, Cupini LM, Rizzato B, et al. Influence of physiologic oscillation of estrogens on cerebral hemodynamics. J Neurol Sci. 2001; 185: 49-53.

25. Krejza J, Mariak Z, Nowacka A, et al. Influence of 17-beta-estradiol on cerebrovascular impedance during menstrual cycle in women. J Neurol Sci. 2004; 221: 61-7.

26. Ibrahimi K, van Oosterhout WP, van Dorp W, et al. Reduced trigeminovascular cyclicity in patients with menstrually related migraine. Neurology. 2015 Jan 13; 84: 125-31.

27. Yücel Y. Migraine headache: Diagnostic and management approaches Dicle Med J. 2008; 35: 2816. 